\title{
New Nutrition Standards Should Shape Americans' Food and Beverage Choices
}

Michelle Winokur, DrPH, and the AfPA Governmental Affairs

Team, Alliance for Patient Access (AfPA)

The Alliance for Patient Access (allianceforpatientaccess.org), founded in 2006, is a national network of physicians dedicated to ensuring patient access to approved therapies and appropriate clinical care. AfPA accomplishes this mission by recruiting, training and mobilizing policy-minded physicians to be effective advocates for patient access. AfPA is organized as a non-profit 501(c)(4) corporation and headed by an independent board of directors. Its physician leadership is supported by policy advocacy management and public affairs consultants. In 2012, AfPA established the Institute for Patient Access (IfPA), a related 501(c) (3) non-profit corporation. In keeping with its mission to promote a better understanding of the benefits of the physician-patient relationship in the provision of quality healthcare, IfPA sponsors policy research and educational programming.

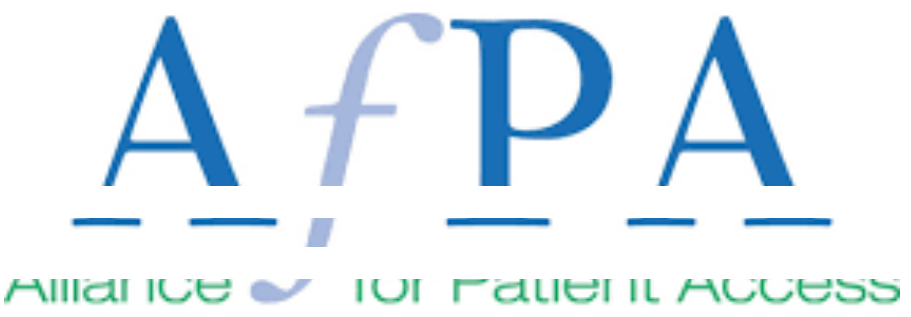

How many serving of seafood should expectant mothers consume per week? How many fruits and vegetables should children have each day? When should babies start on solids?

Many parents, and even some health care providers, many not be certain. But consulting the new Dietary Guidelines for Americans will provide the answers. (1)

The Dietary Guidelines are updated jointly by the U.S. Departments of Agriculture and Health and Human Services every five years. The agencies released the newest edition in late December. Under the call to action "Make Every Bite Count," the new Dietary Guidelines provide a framework for healthy eating at each stage of life.

The latest version of the Dietary Guidelines includes, for the first time, information about nutrition for infants and toddlers. Evidence has shown birth through age 2 is a pivotal time of growth and development. "It also is key for establishing healthy dietary patterns that may influence the trajectory of eating behaviors and health throughout the life course," according to the document.

Key recommendations for infants and toddlers include:

- $\quad$ Feeding an exclusively human milk diet for the first six months of life. The Dietary Guidelines suggest sourcing pasteurized donor human milk from a reliable source, such as an accredited bank, if mother's milk isn't available. Feeding infants iron-fortified formula is the acceptable alternative to human milk.

- Provide infants with supplemental vitamin D soon after birth.

- $\quad$ Introduce nutrient-dense complementary foods around 6 months of age. Potentially allergenic foods, such as peanuts, egg, cow milk products and wheat, should be introduced along with other complementary foods.

- $\quad$ Avoid foods and beverages with added sugars, and limit foods and beverages higher in sodium.

- Encourage eating foods from all food groups. Foods rich in omega 3s, iron, zinc, and vitamin D, such as seafood, are important for introducing nutrients crucial for development.

The new Dietary Guidelines also offer expanded guidance for pregnant and breastfeeding women. Consumption charts of various foods show these groups of women, on average, eat less than the recommended amounts of vegetables, whole grains and seafood. Two to three servings, totaling 8-12 ounces, of seafood choices lower in methylmercury per week has been shown to provide nutritional value to mothers and to benefit their babies, including babies' brain development.

\section{"Consumption charts of various foods show these groups of women, on average, eat less than the recommended amounts of vegetables, whole grains and seafood."}

Finally, the Dietary Guidelines offers three principles for everyone to consider when making food and beverage selections:

1. Meet nutritional needs primarily from nutrient-dense foods and beverages.

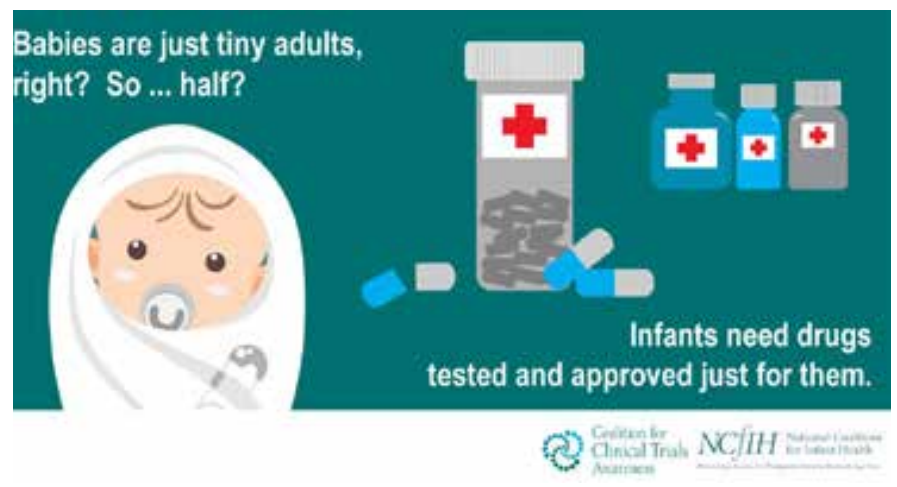


What's the difference between the Dietary Guidelines Advisory Committee Report \& the Dietary Guidelines for Americans?

\section{COMMITTEE REPORT V VS DIETARY GUIDELINES}

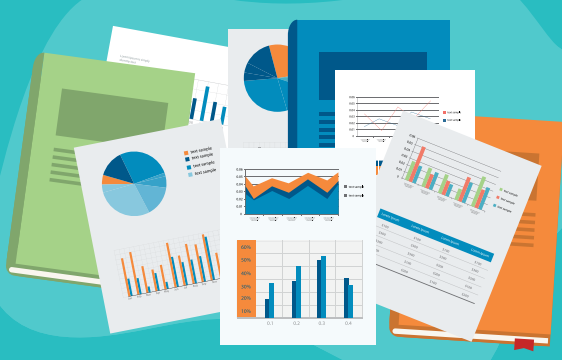

An overview of the latest available science on a variety of nutrition topics

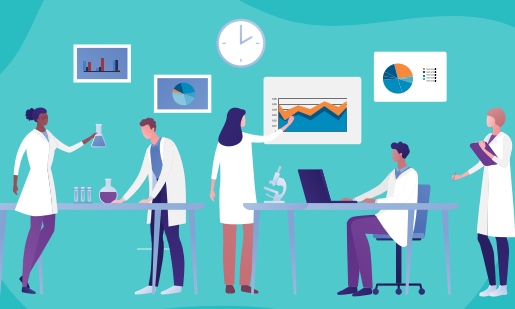

The Dietary Guidelines Advisory Committee, a balanced group of nutrition science experts

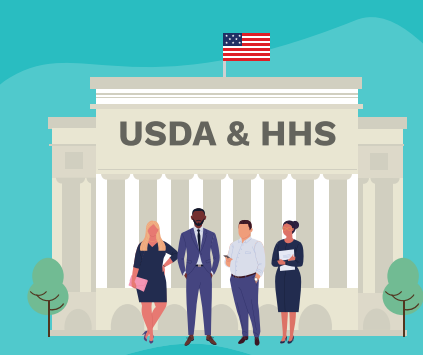

U.S. Department of Agriculture (USDA) and U.S. Department of Health and Human Services (HHS)

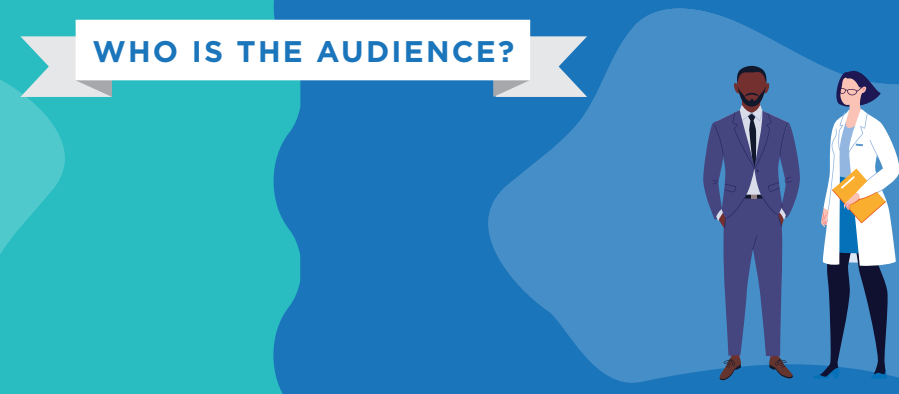

Nutrition policymakers and health professionals

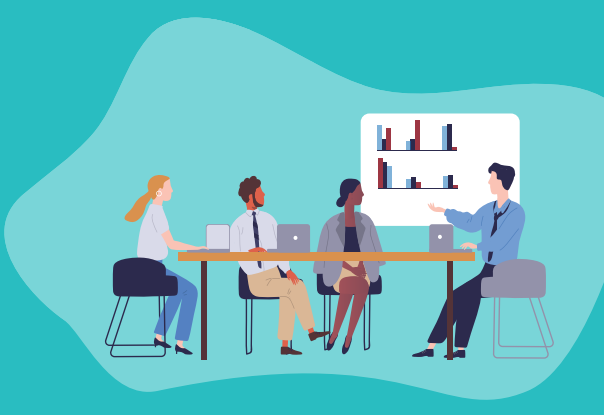

Informs USDA and HHS as they develop the Dietary Guidelines for Americans

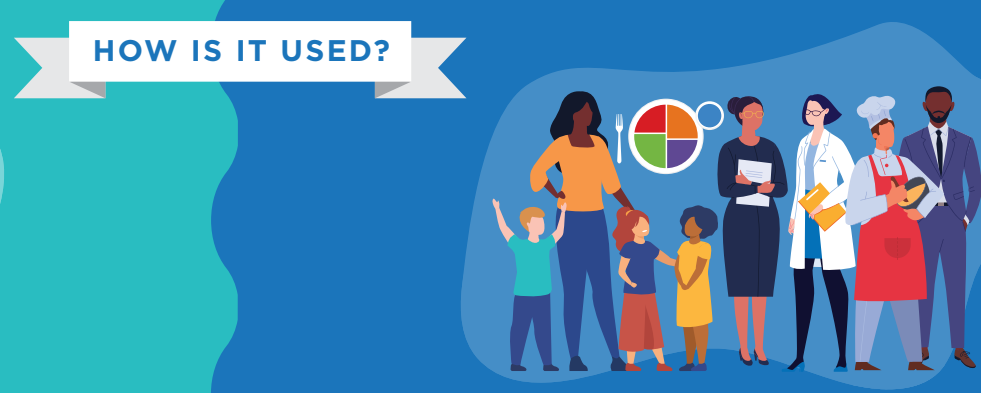

Used as the basis for federal nutrition policy; adapted by medical professionals to meet specific needs; developed into nutrition resources for the general public; and much more 


\section{THE DIETARY GUIDELINES FOR AMERICANS CAN HELP YOU EAT HEALTHY TO BE HEALTHY}

The Dietary Guidelines for Americans provide science-based advice to help everyone-no matter their age, race, socioeconomic, or health status-achieve better health by making every bite count.

\section{Americans Do Not Follow the Dietary Guidelines and Our Health Is Suffering}

\section{Healthy Eating Index-2015 Scores} , Over Time

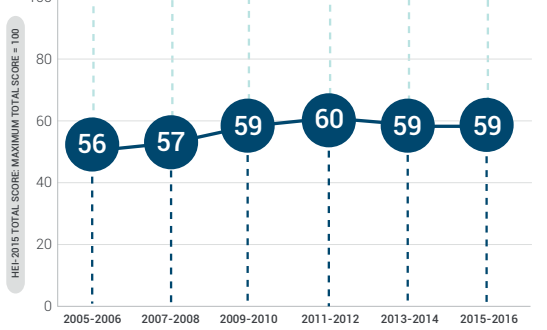

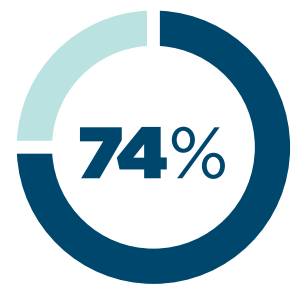

of American adults are overweight or obese
6IN10 ADULTS are living with one or more diet-related chronic diseases

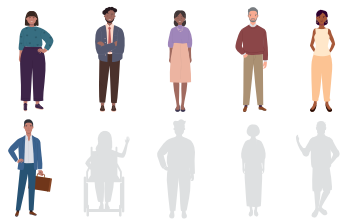

The Science Behind the Dietary Guidelines Represents Americans

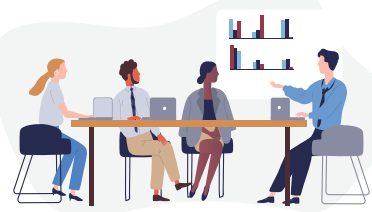

The Dietary Guidelines is based on science that examines how diet promotes health and prevents disease in:

People who are healthy

People at risk for diet-related chronic diseases

Some people who live with diet-related chronic diseases

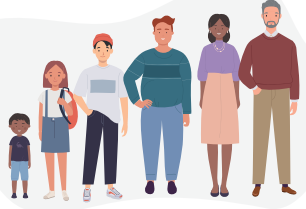

And the evidence base reflects the diversity of Americans, including:

All ages and life stages

Different racial and ethnic backgrounds

A range of socioeconomic statuses

\section{Following the Dietary Guidelines Can Help Improve Americans' Health}

Each step closer to eating a diet that aligns with the Dietary Guidelines is associated with:

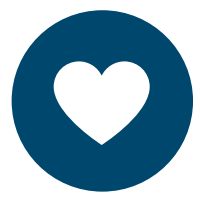

Lower Risk of Heart Disease

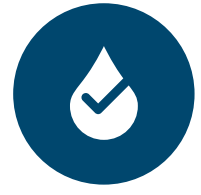

Lower Risk of

Type 2 Diabetes

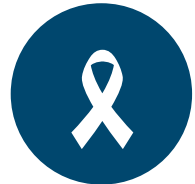

Lower Risk of Cancer

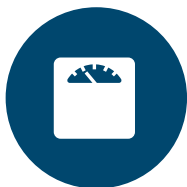

Lower Risk of Obesity

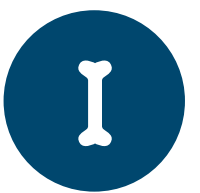

Lower Risk of Hip Fracture

For more information about the Dietary Guidelines, visit DietaryGuidelines.gov. 
2. Choose a variety of options from each food group: vegetables, fruits, grains, dairy and protein foods.

3. Pay attention to portion size.

Following these principles can help Americans of every age make healthy dietary choices. "A fundamental premise of the 2020-2025 Dietary Guidelines is that just about everyone, no matter their health status, can benefit from shifting food and beverage choices to better support healthy dietary patterns," notes its executive summary.

The Dietary Guidelines are the product of an extensive review of the most current research and medical knowledge on a variety of specific nutrition topics. The final version also incorporates public comments along with input from other federal agencies.

To learn more, visit the Dietary Guidelines for Americans website, which includes the recommendations in English and Spanish, as well as other consumer-friendly resources. (1)

\section{References:}

U.S. Department of Agriculture and U.S. Department of Health and Human Services. Dietary Guidelines for Americans, 2020-2025. 9th Edition. December 2020. Available at DietaryGuidelines.gov and https://www. dietaryquidelines.gov/resources/downloadable-graphics

Disclosures: The author reports no disclosures

NT

\begin{tabular}{l} 
Corresponding Author \\
\\
Michelle Winokur, DrPH, \\
Policy Communications Director \\
Alliance for Patient Access (AfPA) Government Affairs Team \\
1275 Pennsylvania Ave. NW, Suite 1100A Washington, DC \\
20004-2417 \\
202-499-4114 \\
info@allianceforpatientaccess.org \\
\hline
\end{tabular}

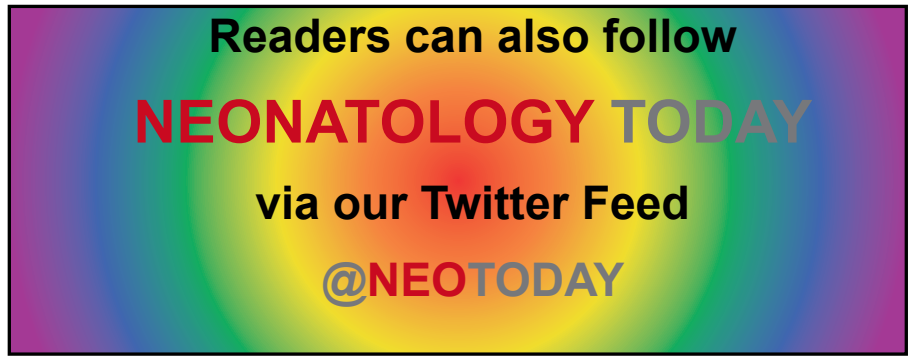

\section{Still a Preemie?}

\section{Some preemies are born months early, at extremely low}

birthweights. They fight for each breath and face nearly

insurmountable health obstacles.

But that's not every preemie's story.

Born between 34 and 36 weeks gestation?

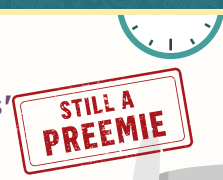

Just like preemies born much earlier, these "late preterm" infants can face:
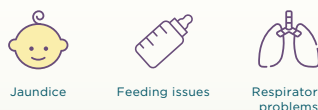

aundice Feeding issues

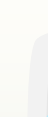

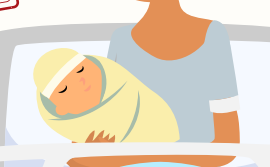

And their parents, like all parents of preemies, are at risk for postpartum depression and PTSD.

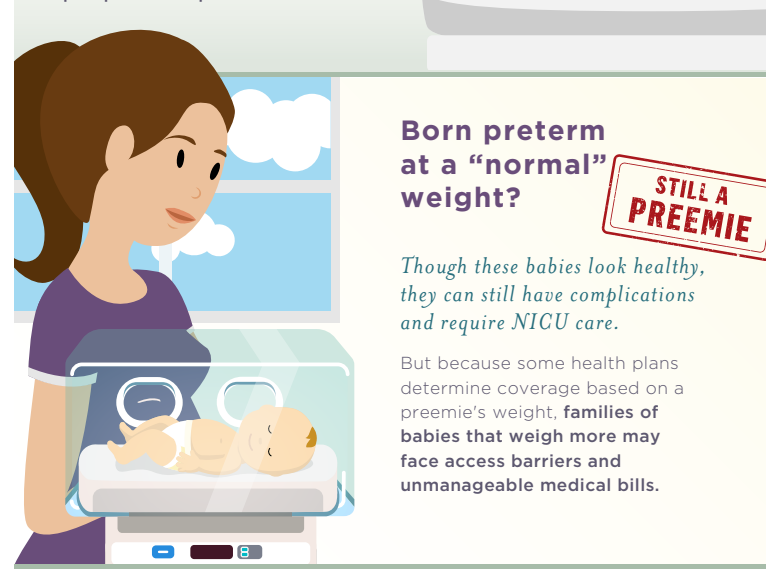

Born preterm but not admitted to the NICU?

Even if preterm babies don't require $\mathcal{N I C U}$ care, they can still face health challenges. Those challenges can extend through childhood, adolescence and even into adulthood.
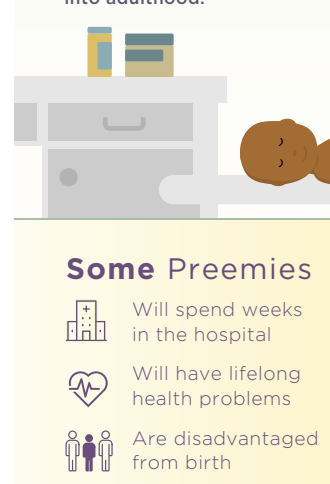

All Preemies

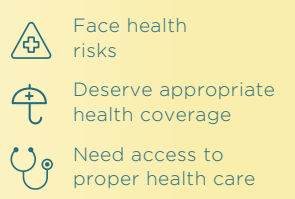

$N C f I H \quad \stackrel{\text { National Colition }}{\text { for Infint Heath }}$ 